\title{
The Influence and Countermeasures of the "COVID-19" on the Economic Development of Coastal Economic Zone of Guangdong Province
}

\author{
Weidong Lai ${ }^{1,2}$, Zhaoxi Deng ${ }^{3}$ \\ ${ }^{1}$ School of Business, Lingnan Normal University, Zhanjiang, China \\ ${ }^{2}$ Guangdong Coastal Economic Belt Development Research Center, Zhanjiang, China \\ ${ }^{3}$ Finance Department, Zhanjiang Preschool Education College, Zhanjiang, China
}

Email address:

natureeast@139.com (Weidong Lai),366861668@qq.com (Zhaoxi Deng)

\section{To cite this article:}

Weidong Lai, Zhaoxi Deng. The Influence and Countermeasures of the "COVID-19" on the Economic Development of Coastal Economic Zone of Guangdong Province. International Journal of Economic Behavior and Organization. Vol. 8, No. 2, 2020, pp. 44-48. doi: $10.11648 /$ j.ijebo.20200802.14

Received: June 5, 2020; Accepted: June 19, 2020; Published: June 28, 2020

\begin{abstract}
In February 2020, the CPC Central Committee defined the epidemic at a meeting which with the theme of "Coordinating the epidemic prevention and control with economic and social development"- "The COVID-19 outbreak is a major public health emergency that has spread in the fastest speed, caused the most extensive infection and is the most difficult to contain in the country since the founding of the People's Republic of China". From this definition, it can be seen that the impact of this epidemic on China is very huge. Sudden outbreak of the COVID-19 inevitably deal a relatively big blow to China's economic and social development. How to adopt effective measures to promote economic and social recovery and development under the working on an ongoing basis to contain the virus is an urgent issue that needs to be resolved. This article takes the Coastal Economic Zone of Guangdong Province as a research object. Analyzes the impact of the epidemic on it, and the difficulties and problems facing the current economic development. In response to these problems, this article makes several suggestions: continued prevention and control of the epidemic situation, increased government support, optimized industrial structure, and promoted economic growth by the Troika. So as to promote Guangdong's economic recovery and further promote Guangdong's economic and social development.
\end{abstract}

Keywords: COVID-19, Coastal Economic Zone of Guangdong Province, Economic and Social Development

\section{Introduction}

Guangdong is adjacent to Hong Kong and Macao and faces Southeast Asia. It is located at the hub of shipping in the Pacific, Indian Ocean, and Atlantic Oceans. It connects internally to major cities and builds foreign trade channels. Guangdong is an important strategic hub for the construction of the "Belt and Road". It is one of the core regions of China's participation in economic globalization and an important window for opening up. It has an extremely important strategic position. At present, a series of measures such as accelerating the integrated development of the Coastal Economic Zone of Guangdong Province, rapid integration into the Guangdong-Hong Kong-Macao Greater Bay Area, deepening the reform of the free trade zone, and constructing a national independent innovation demonstration zone in the Pearl River Delta are accelerating Guangdong 's move from an open economic big province to an open economy strong province.

The Sudden outbreak of the COVID-19 has impacted the economic and social development of Guangdong. According to statistics from the Guangdong Bureau of Statistics, in the first quarter of 2020, the GDP of Guangdong Province was $22,518.67$ billion yuan, a decrease of $6.7 \%$ year-on-year. Among them, the added value of the primary industry was 87.660 billion yuan, a decrease of $0.3 \%$ year-on-year; the added value of the second industry was 797.807 billion yuan, a decrease of $14.1 \%$ year-on-year; the added value of the tertiary industry was 1.3664 trillion yuan, a decrease of $1.5 \%$ year-on-year, as shown in Figure 1. It can be seen from the 
figure 1 that in the GDP of Guangdong in the first quarter of 2020, the secondary and tertiary industries had a greater impact, showing a cascading decline. Among them, Tourism, accommodation, catering, retail, transportation, import and export had been greatly affected by the epidemic. After months of combating the pandemic, Guangdong started to resume work and normal life step by step under the strong leadership of the CPC Central Committee and the coordinating epidemic control of provincial government. According to the epidemic situation, various regions applied a flexible approach to the resumption of work. The economic and social development had been witnessing positive changes [1].

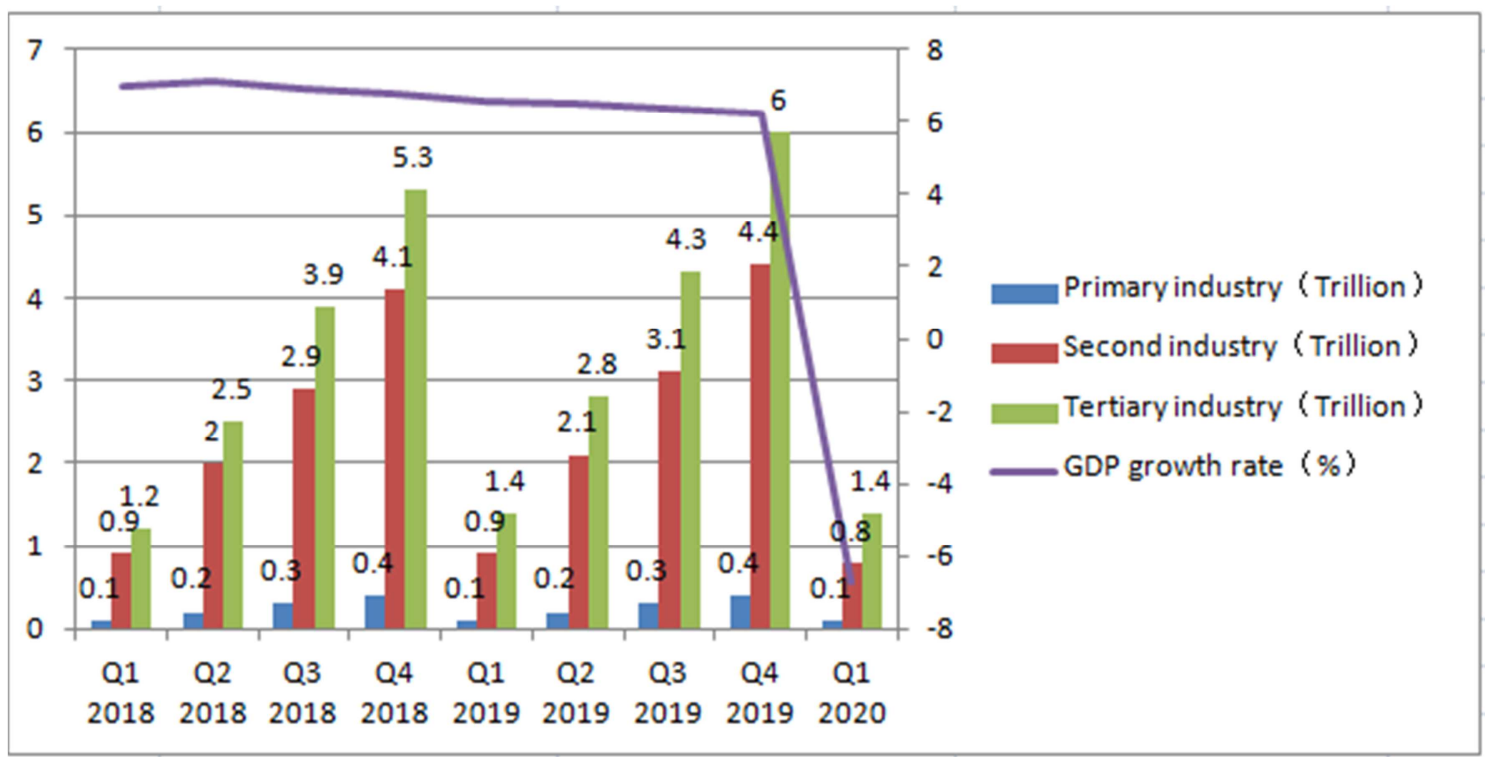

Figure 1. The GDP of Guangdong by industry from Q1 2018 to Q1 2020.

\section{The Difficulties Faced in Resuming Production and Operation}

Under the strong leadership of the Party Central Committee with Comrade Xi Jinping at the core, and under the careful deployment of the Provincial Party Committee and the Provincial Government, the people united as one and worked together to overcome difficulties and fight against the COVID-19. Through the unremitting efforts of everyone, the epidemic prevention and control has achieved periodic results, and the economic and social order of our province has been effectively restored step by step. However, as the international epidemic continues to spread, "to forestall imported infections and domestic resurgence" is the arduous tas, and the challenges facing our province's economic development are unprecedented [2].

\subsection{The Epidemic Was Still Spreading}

After several months of "anti-epidemic", under the strong leadership of the Party Central Committee and the joint efforts of the broad masses of the people in the country, the epidemic situation in most parts of China is almost at the end. The epidemic prevention and control situation has continued to improve, and the order of production and life has also been restored quickly. Overall efforts to promote the prevention and control of epidemic situation achieved positive results. However, the spread of overseas epidemic situation is increasing. The overseas epidemic situation affected the development of the global economy, and brought new challenges to China's epidemic prevention and control at the same time. China will make preventing imported cases the top priority in its COVID-19 response at present and even for a "prolonged" period of time.

\subsection{The Normal Operation of the Enterprise Was Affected}

During the epidemic situation, in order to do a good job in prevention and control, most enterprises were in a state of shutdown and other enterprises suspend or limit production. The enterprises cannot operate normally. At the beginning of March, as the prevention and control situation of the epidemic continued to improve, enterprises resumed work one after another. But they still faced the dilemma of resuming work with insufficient output. There are three main reasons for their investigation: One is that Some important production resources, such as raw materials and components, are affected to varying degrees in all links of the entire production supply chain. Delayed delivery and failure to deliver according to quality occurred frequently, which seriously affects the company normal operation. Secondly, due to the epidemic situation, employment also faced great challenges. "How to ensure that employees return to work on time?" And "How to ensure that employees return to work safely?" A series of issues were also the focus of enterprises. The third is the reduction of orders, which makes it difficult for enterprises. Affected by the epidemic, if demand decreases, orders will be relatively reduced, especially the spread of foreign epidemics, overseas orders have fallen sharply, which directly led to the 
company's lack of income and blocked operations.

\subsection{The Foreign Trade Was Facing Great Difficulties}

Under the severe and complicated economic environment, Guangdong fully exerts its role as a bridgehead for reform and opening up. Guangdong grasps the opportunities brought by the "Belt and Road", integrates into the construction of the Guangdong-Hong Kong-Macao Greater Bay Area, and joins the international competition in an open and proactive manner. According to statistics, in 2019, after reaching a record high of 7.16 trillion yuan in 2018, Guangdong's foreign trade continued to stabilize at the 7 trillion yuan mark, leading Jiangsu, Shanghai, Zhejiang, Beijing and other major foreign trade provinces in China. However, affected by the epidemic, in the first quarter of 2020, Guangdong 's foreign trade reached 1.37 trillion yuan (RMB), down $11.8 \%$ from the same period last year. There was Sino-US trade friction in the past, and the impact of the epidemic situation at home and abroad. The difficulties and challenges of double superposition had a great impact on the development of foreign trade. How to change the status quo and promote the balanced development of foreign trade is currently urgently needed to be resolved.

\subsection{Employment Issues Were Prominent}

With the impact of the epidemic, all industries in our province have encountered unprecedented shocks, and employment conflicts have become more intense. First of all, according to the unified accounting of the National Bureau of Statistics, in 2019, the ratio of the three major industrial structures in Guangdong is 4.0: 40.5: 55.5, of which the tertiary industry exceeds $55 \%$, and most tertiary industries are labor-intensive industries that can absorb more employment. The COVID-19 has the greatest impact on the tertiary industry, leading to worsening unemployment [3]. Secondly, it is more difficult for college students to find employment. Under the continuous influence of the epidemic, some enterprises cannot operate normally, resulting in a large number of layoffs and even bankruptcy. In addition, the postponement of the company's resumption of work and the cancellation of recruitment have undoubtedly caused great difficulties in the employment of college students in this college graduation season. Finally, it is more difficult for laid-off workers, migrant workers and other vulnerable groups to re-employ, which seriously affects their lives.

\subsection{The Transportation Industry Was Seriously Affected}

With the spread of the epidemic, enterprises such as rail, road, air, sea and postal industries were strangled. To reduce the spread of the epidemic, provinces and cities have also increased their control of traffic. In addition, the measures taken to prevent the spread of the epidemic, such as staff diversion, shift adjustment, sanitary inspection, and equipment disinfection, have caused these enterprises to increase their costs and expenses, reduce their revenues, and cause serious losses for transportation companies.

According to statistics, the shipment volume of Guangdong railway goods out of the province was 23027 vehicles in January, a decrease of $40 \%$ year-on-year. By the end of the first quarter, with the improvement of the epidemic situation, the economic activity of various regions gradually recovered, and the volume of railway freight shipments in Guangdong Province had shown a substantial recovery. The volume of delivery in April was 31,633 vehicles, a decrease of $20 \%$ year-on-year. The transportation gradually recovered with the control of the epidemic, but there is still a certain gap compared with the same period.

\subsection{The Tourism Industry Was Hit Hard}

The official website of the Guangdong Provincial Department of Tourism and Culture has issued multiple reports. The report shows that in the first quarter of 2020 , tourist attractions were expected to lose 7.76 billion yuan, and the direct economic losses of tourist hotels exceed 50 billion yuan. Passenger flow in tourist attractions fell by $90 \%$ year-on-year, and the opening rate of tourist hotels was less than 10\%. The COVID-19 stopped the country's tourism activities in an all-round way and caused the original sunrise industry to fall to a freezing point. The impact of such a big impact on tourism is related to its own industry characteristics. First, tourism is not a necessity of life. Second, tourism is greatly affected by economic and social development. Third, the outstanding events will have a direct impact on tourism, such as "Crisis", "SARS", "COVID-19 " and so on. Tourism still needs a considerable period of time to recover.

\subsection{Farmers' Income Was Difficult to Increase}

In recent years, with the continuous improvement of agricultural production efficiency, the total agricultural output value has increased year by year. The provincial statistics bureau released data on the economic performance of Guangdong in the first quarter of 2020, showing that the output value of Guangdong 's agriculture (planting industry) increased by $6.0 \%$, an increase of 1.5 percentage points year-on-year. The output of garden fruits, vegetables, poultry meat and eggs increased by $8.6 \%, 4.7 \%, 12.1 \%$ and $6.5 \%$. Agricultural development has been steadily increasing, but with the impact of the epidemic, the circulation of agricultural products has been severely hindered, and sales have been poor, resulting in difficulties for farmers to increase income [4].

\section{Countermeasures and Suggestions}

\subsection{Implement Regular Epidemic Prevention and Control Measures, Promote the Coordinated Enterprises Resumption}

The epidemic is spreading globally. In the era of globalization, we face the same challenges, shoulder common responsibilities and have a shared future. Thanks to the painstaking efforts of the whole province and society, Guangdong has achieved major progress in containing the outbreak, and life and work is returning to normal at a faster 
pace in our province. But we still need to continue to unswervingly pay close attention to all prevention and control work. No victory should be lightly announced until there is a complete win. One is to strengthen confidence, the other is to implement it vigorously, the third is to grasp the details, and the fourth is not to relax. Under the regular epidemic prevention and control, the low-risk regions are fully resumed work and resumed production, the medium-risk regions are orderly restored to production and living order, and the high-risk regions should do best in the epidemic prevention and control first and then resume work. Advance economic and social development in an orderly manner.

\subsection{Optimize the Industrial Structure and Promote the Development of New Formats}

The spread of the COVID-19 has brought unprecedented impact and difficulties to the economic and social development of China and the world. Among them, the impact of the epidemic on industrial restructuring is even more profound. On the one hand, traditional industries had suffered the most; on the other hand, the epidemic had spawned and promoted the development of some new industries and new formats. Therefore, we must accordance the requirements of "grasping the epidemic prevention and control with one hand, and resuming work and production with the other hand". First ensure that industries related to basic life such as eating, wearing, and protective materials, Transportation, etc. are given priority to normal operation, and protect the normal life of the people [5]. Secondly, vigorously develop modern types of public service industry, especially health and medical service industry. Plan and construct major public health infrastructure to drive the development of related industries. Third, Take $5 \mathrm{G}$ as an opportunity to promote the development of online industries. "Internet + transportation", "Internet + agriculture", "Internet + education", "Internet + medical" [6], "Internet + tourism", "Internet + logistics" and other new types of digital industries will become increasingly important. Use information and communication technologies and Internet platforms to allow the Internet to deeply integrate with traditional industries and create a new development ecology [7].

\subsection{Increase Government Support to Help Companies Resume}

In response to the epidemic situation, the central and local governments have successively issued a series of policy measures. On the one hand, these measures must be implemented as early and carefully as possible. On the other hand, it is necessary to introduce some new policy measures in a timely manner according to the changes in the specific situation in our province. First, advancing tax and fee cuts [8]. one is according to the development situation of the epidemic situation, appropriate reduction and exemption of value-added tax and corporate income tax in tourism, transportation, catering, accommodation, retail and other industries to reduce burden and costs for enterprises. The second is to reduce the cost burden of the enterprise by reducing or exempting the social security contribution rate and the old-age medical contribution rate of the enterprise. Secondly, giving the enterprise appropriate financial subsidies. Direct subsidies and loan discounts can be combined to help companies quickly solve problems in the capital chain, industrial chain, and supply chain [9]. Thirdly, enterprises in difficulty can apply for the deferral of related taxes or extend the deferred period appropriately [10]. Exemption of taxes and fees during the deferred payment period can reduce the cost of the enterprise to a certain extent and reduces the pressure on the enterprise.

\subsection{Drive the "Troika" and Promote Economic Growth}

First, increase investment. Pay close attention to the investment and construction of key new infrastructure projects [11], especially in the fields of medical and health care, key science and technology projects, scientific research, public service construction, agricultural and rural facilities, and increase the intensity of new investment projects, while ensuring that major projects are timely start.

Second, strengthen support for export enterprises [12]. One is to reduce the operating costs of exporting enterprises by means of tax reduction, fee reduction and export tax rebate. The second is to optimize the management and methods of key businesses such as trade credit, trade financing, and re-export trade. The third is to use new technologies to optimize the foreign trade structure. Develop new foreign trade services with the help of emerging technologies such as $5 \mathrm{G}$, Internet, and big data. And promote the optimization of foreign trade structure through remote office, telemedicine, cloud video technology, and cross-border e-commerce services.

Third, create new consumption hot spots and promote new economic growth points. According to previous experience, after the epidemic, there will be a certain degree of "explosive" consumption tide, so new consumption hot spots will drive the economic and social recovery and development of our province. One is to optimize tourism [13]. This outbreak has a huge impact on the tourism market in China and the world, and it is also a challenge to the tourism industry. Under the premise of normalization of epidemic prevention and control, first of all, we must accelerate the structural reform of the optimized tourism industry and upgrade tourism products [14]. Affected by the epidemic, self-driving tours, high-speed rail tours, and peripheral tours are currently preferred, and leisure, wellness, and entertainment are the main purposes. Therefore, tourist attractions should speed up the adjustment of tourism product structure and gradually increase the number of tourists. In addition, improve the construction of public facilities and enhance the services of the scenic spots level. Use $5 \mathrm{G}+\mathrm{VI}$ technology to promote online "cultural tourism consumption action". Through online experience and joint high-quality tour groups, to create a batch of offline boutique tourism, thereby promoting the development of tourism. The second is to upgrade traditional consumption and promote new consumption. Subsidies help traditional consumption such as automobiles, 5G terminals, and green homes. Develop Internet celebrities, live broadcast 
economy, and promote commercial digitization [15]. Develop community marketing to promote the development of emerging commercial circle. Extend new consumption periods and improve new consumption chains. The third is to encourage important groups to take the lead in spending, and coordinate the funds to issue consumer coupons [16]. Boost domestic demand and revitalize consumption. Through the circular chain of "stimulating consumption---promoting production---increasing employment---increasing income---expanding consumption" to promote economic growth.

\section{Conclusion}

Difficulties are only temporary. As long as the whole country works together, the difficulties will be resolved and the epidemic will end. For the epidemic, we cannot relax. Attach equal importance to both epidemic prevention and control and economic development, and strong and swift action to them. According to the state of the epidemic, we should gradually resume work and resume production. Government forces and social forces are combined to jointly promote social and economic recovery and development. Under the regular epidemic prevention and control, we should steadily promote relevant measures to promote Guangdong's economic recovery and further promote Guangdong's economic and social development. Attach equal importance to both

\section{References}

[1] Zhao Hongjun. The Impact and Enlightenment of the New Coronary Pneumonia Epidemic on China's Regional Economic Development [J]. Regional Economic Review, 2020 (2).

[2] Coordinate the prevention and control of normal epidemic situation and economic and social development $[\mathrm{N}]$. Nanfang Daily. 2020 (A04).

[3] Liu Anchang. The economic impact and financial hedging policy of the "New Crown" epidemic on my country-a comparative analysis of the "SARS" epidemic. Lanzhou Academic Journal, 2020: 59-70.
[4] Zhang Liyu. Impact of New Coronary Pneumonia Epidemic Situation on Animal Husbandry Production and Response Suggestions [J]. China Feed, 2020 (5): 3-4.

[5] Liang Peng, Xing Lixia. Impact of New Coronary Pneumonia Epidemic on Catering Industry and Countermeasures $[\mathrm{J}]$. Times Economics and Trade, 2020 (7).

[6] Li Dacan, Huang Min, Zhao Cailian, et al. Construction of 5G Smart Medical Service System in the Prevention and Control of New Coronary Pneumonia [J]. Chinese Journal of Emergency Medicine, 2020, 29 (04): 503-508.

[7] Wang Weiling. Research on the Development of Digital Economy under the Influence of New Coronary Pneumonia [J]. Economic Aspect, No. 412 (03): 16-22.

[8] $\mathrm{Hu}$ Yanni, Zhang Lin. Economic Policy Analysis and Suggestions for Dealing with New Coronary Pneumonia [J]. Information Communication Technology and Policy, 2020 (2).

[9] Han Heyuan. How Guangdong should take action to stabilize the economy in response to the impact of the epidemic. Securities Times, 2020: A30.

[10] Chen Ling. Do a good job of epidemic prevention and control and economic and social development as a whole $[\mathrm{J}]$. Decision Exploration, 2020 (6): 1-1.

[11] Witnessing the confidence and potential of opening up Guangdong [N]. Nanfang Daily. 2020 (A04).

[12] Wang Tieshan. The Impact of New Coronary Pneumonia Epidemic on my country's Foreign Trade Enterprises and the Countermeasures [J]. Economic Aspect, No. 412 (03): 23-29.

[13] Huang Yujun. Research on Economic Promotion Measures under the Epidemic Situation-Taking Jiashan County, Zhejiang Province as an Example. Modern Business Industry, 2020 .

[14] Feng Xiaoxu. Impact of New Coronary Pneumonia Epidemic on Tourism and Countermeasures [J]. Chinese Circulation Economy (03).

[15] Song Qinghui. The new crown pneumonia epidemic has spawned two new economic formats. The Chinese business community, 2020.

[16] Wan Fuyang. Analysis of the influence of "coupon" on consumer behavior [J]. Modern Business, 2019, 000 (006): $5-6$. 